\title{
NEMATÓIDES ASSOCIADOS AO AMENDOIM FORRAGEIRO E A BANANEIRA NO ESTADO DO ACRE
}

\author{
MARIA DE JESUS B. CAVALCANTE ${ }^{1}$, RAVI D. SHARMA ${ }^{2}$, JUDSON F.VALENTIM ${ }^{1}$ \& TARCÍSIO M.S. GONDIM ${ }^{1}$
}

\author{
'Embrapa Acre, Cx. Postal 321, CEP 69908-970, Rio Branco, AC, maju@cpafac.embrapa.br; \\ ${ }^{2}$ Embrapa Cerrados, Cx. Postal 08223, CEP 73301-970, Planaltina, DF
}

(Aceito para publicação em 03/09/2001)

Autor para correspondência: Maria de Jesus Barbosa Cavalcante

\section{ABSTRACT \\ Nematodes associated with forage peanuts and banana plantations in the State of Acre}

Six species of plant nematodes were identified in the rizosphere of forage peanuts (Arachis pinto $i$ and Arachis glabrata) with the following frequencies of occurrence: Aphelenchoides sp. (100\%), Criconemella sp. (100\%), Ditylenchus sp. (100\%), Pratylenchus brachyurus (86\%), Paratrichodorus minor sp. (71\%), e Xiphinema sp. (29\%). The followings were identified in the rizosphere of banana (Musa sp.): Helicotylenchus multicinctus (245), H. dihystera (88), Criconemella sp. (5), Tylenchus sp. (15), Aphelenchoides sp. (13), Meloidogyne sp. juvenile (3), Ditylenchus sp. (2), and Pratylenchus sp. juvenile (1) and Aphelenchus avenae (1). This is the first report on the occurrence of plant parasitic nematodes in forage peanuts and banana fields in the State of Acre.
No Estado do Acre, o amendoim forrageiro representado pelas espécies Arachis pintoi Krapovickas y Gregory e Arachis glabrata Benth (American Peanut Research and Education Society:47-133, 1973) vem sendo estudado intensivamente, como opção para diversificação dos sistemas de produção de forragem, sistemas silvipastoris, para a cobertura do solo em culturas perenes e em sistemas agroflorestais em alguns Estados do Brasil (Valentim, Embrapa-CPAF-AC Boletim de Pesquisa 10:28,1996; Andrade, Revista Brasileira de Zootecnia 28:439, 1999). A cultura da banana (Musa sp.), principal produto frutícola do Acre, ocupando uma área de 5.025 ha com uma produtividade de 1.083 cachos/ha, representa uma das principais fontes de renda para o agricultor (IBGE, http://www. sidra.ibge.gov.br., 2000). O crescimento do consumo local e a conquista dos mercados do Amazonas, Rondônia, Mato Grosso e Goiás vêm incrementando o plantio dessa Musaceae em novas áreas. Com essa ampliação, diversos problemas fitossanitários apresentam-se como ameaça para a cultura, considerando a utilização generalizada das cultivares Prata, Maçã e D'Angola (Comprida), suscetíveis a diversas doenças (Ledo, Embrapa CPAF-AC, Folder, 1998).

O presente trabalho teve como objetivo assinalar nematóides potencialmente fitopatogênicos, associados a A. pintoi, A. glabrata e bananeiras, com sintomas de amarelecimento e clorose de folhas, em campos de experimentos de introdução, avaliação e adaptação de germoplasma do gênero Arachis e bananeiras da coleção da Embrapa Acre.

Foram coletadas, na área experimental da Embrapa Acre, em março de 2000, sete amostras compostas de solo e raízes em campos de $A$. pintoi e $A$. glabrata cv. Arbrook e cinco amostras simples de solo e raízes, em rizosfera de bananeira cv. Terra. Os nematóides foram isolados de $100 \mathrm{~g}$ de solo e $10 \mathrm{~g}$ de raízes pelo método modificado de Coolen [RootKnot nematodes (Meloidogyne species: systematics, biology and control. London: Academic Press, 1979]. As densidades populacionais dos nematóides foram feitas com auxílio da câmara de Peter, em microscópio óptico.

Seis fitonematóides de grande potencial fitopatogênico foram identificados associados ao amendoim forrageiro, nas seguintes freqüências de ocorrência nas amostras: Aphelenchoides sp. Fisher, 1936 (100\%), Criconemella sp. De Grisse \& Loof, 1965 (100\%), Ditylenchus sp. Filipjev, 1936 (100\%), Pratylenchus brachyurus Filipjev, 1936 (86\%), Paratrichodorus minor Siddiqi, 1974 (71\%) e Xiphinema sp. (29\%). Os nematóides P. minor e Xiphinema sp. são transmissores de vírus de planta. Na bananeira, um total de sete fitonematóides foram encontrados nas amostras avaliadas, com destaque para as espécies do nematóide espiralado, Helicotylenchus multicinctus (Cobb, 1893) Golden, 1956, H. dihystera (Cobb, 1893) Sher, 1961. A primeira causa nematose de alta severidade na bananeira (A.G. Whitehead, Plant Nematode Control. CAB International, Wallingford, UK. 1998). As densidades de $H$. multicinctus e $H$. dihystera foram 245 e 88 , respectivamente. Os demais fitonematóides encontrados associados à bananeira cv. Terra foram: P. brachyurus, Aphelenchoides sp., Ditylenchus sp., Criconemella sp. e Meloidogyne sp. Goeldi, 1887. Na atualidade, Meloidogyne spp. é de alto poder destrutivo em relação à bananeira, especialmente no Estado de Pernambuco e Piauí (Moura, R. M., UFRPE, informação pessoal). Os gêneros Aphelenchoides e Ditylenchus comportam espécies micobívoras, sendo necessário futuras identificações específicas. Este trabalho estabelece as primeiras citações de ocorrência de nematóides associados ao amendoim forrageiro e à bananeira no Estado do Acre. 